\title{
An Innovative Hydrogen Peroxide-Sensing Scaffold and Insights Towards its Potential as an ROS-Activated Persulfide Donor
}

Rynne A. Hankins, S. Israel Suarez, Madison A. Kalk, Nolan M. Green, Megan N. Harty, and John C. Lukesh, III*

Department of Chemistry

Wake Forest University

Wake Downtown Campus, Winston-Salem, NC 27101 (USA)

E-mail: lukeshjc@wfu.edu

\begin{abstract}
Reactive sulfur species, such as hydrogen sulfide, persulfides, and polysulfides, have recently emerged as key signaling molecules and important physiological mediators within mammalian systems. To further assess the therapeutic potential of their exogenous administration, we report on the development of a unique hydrogen peroxide $\left(\mathrm{H}_{2} \mathrm{O}_{2}\right)$-sensing motif and its capacity for providing cellular protection against oxidative stress while serving as a reactive oxygen species (ROS)-activated persulfide donor. With the strategic implementation of a gemdimethyl group that promotes both cyclization and stability, we found the initial rate of payload release from this newly derived scaffold to be directly proportional to the concentration of $\mathrm{H}_{2} \mathrm{O}_{2}$ and to proceed via an unprecedented pathway that avoids the production of electrophilic byproducts, a severe limitation that has plagued the physiological application of previous designs.
\end{abstract}

\section{Introduction}

Hydrogen sulfide $\left(\mathrm{H}_{2} \mathrm{~S}\right)$ has recently been implicated as a key signaling molecule within mammalian systems, mediating numerous physiological processes related to inflammation, the brain and central nervous system, and the cardiovascular system. ${ }^{[1-3]}$ In fact, along with nitric oxide (NO) and carbon monoxide (CO), $\mathrm{H}_{2} \mathrm{~S}$ has now established itself as an enduring member of the gasotransmitter family, a well-known class of gaseous, cell-permeable signaling molecules. $^{[4-6]}$

Since the early 2000s there has been an exponential increase in the number of studies that have been published related to hydrogen sulfide and its physiological significance. However, with protein persulfidation (Cys-SH to Cys-SSH) believed to be a primary mechanism by which $\mathrm{H}_{2} \mathrm{~S}$ relays its signaling, many of the physiological effects that were once attributed to $\mathrm{H}_{2} \mathrm{~S}$ may, in fact, be mediated by other reactive sulfur species (RSS), such as persulfides (RSSH) and polysulfides. ${ }^{[7-10]}$

Like hydrogen sulfide, persulfides also display enhanced nucleophilicity and are more potent reductants than their thiol counterparts within a biological setting (i.e. glutathione). ${ }^{[1,12]}$ This is attributed to both the alpha effect and the suppressed $\mathrm{pK}$ a $\mathrm{RSSH}$ which results in the more reactive RSS- being its dominant form at neutral $\mathrm{pH}^{[13]}$ However, in addition to high nucleophilicity, persulfides also possess sufficient electrophilic character. ${ }^{[14,15]}$ Consequently, via thiol-persulfide exchange reactions, persulfides do have the ability to promote the direct persulfidation of protein thiols while also serving as valuable $\mathrm{H}_{2} \mathrm{~S}$ donors themselves.

Since $\mathrm{H}_{2} \mathrm{~S}$ and $\mathrm{RSSH}$ enjoy distinct chemical advantages over their thiol relatives, it likely ensures the biological importance and participation of both of these species in not only redox signaling, but in providing cellular protection as well. In earlier attempts to assess the natural biological functions of reactive sulfur species, inorganic salts, such as sodium sulfide $\left(\mathrm{Na}_{2} \mathrm{~S}\right)$ and sodium hydrosulfide (NaHS), were employed as convenient precursors to $\mathrm{H}_{2} \mathrm{~S} .{ }^{[16,17]}$ However, given that their addition to buffered solutions results in a rapid increase in $\mathrm{H}_{2} \mathrm{~S}$ concentrations, these inorganic salts not only engendered toxicity, but they poorly mimicked the natural slow and steady enzymatic production of hydrogen sulfide. 
Given the clear limitations of inorganic salts in biological studies, several small molecule donor compounds have since been developed that were chemically engineered to release $\mathrm{H}_{2} \mathrm{~S}$, and other reactive sulfur species, via hydrolysis ${ }^{[18]}$ or in response to a specific biological trigger, such as cellular thiols or enzymes. ${ }^{[19-31]}$ Indeed, many of these donors were shown to more closely mimic the natural production of RSS, producing more favorable physiological responses. ${ }^{[32-35]}$ Of particular interest to us, however, were the reported donors of Pluth, Matson, and Chakrapani which were shown to selectively release $\mathrm{H}_{2} \mathrm{~S}$ precursors in response to oxidative stress. ${ }^{[36-40]} \mathrm{A}$ distinct advantage of these donors is not only their potential to further elucidate the physiological effects of $\mathrm{H}_{2} \mathrm{~S}$ (or other RSS) on systems which are under oxidative stress, but they, in particular, are likely to better gauge the therapeutic potential and ability of RSS to combat oxidative stressrelated diseases.

\section{prior studies}
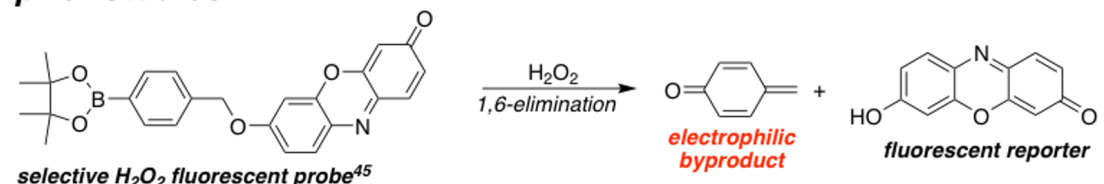

Chem. Eur. J. 2015, 21, 15167-15172
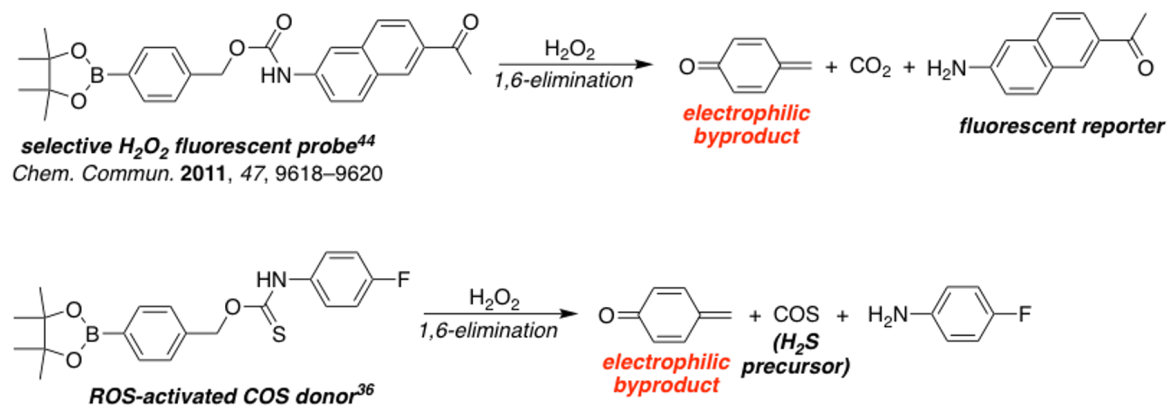

Angew. Chem. Int. Ed. 2016, 55, 1463-14642

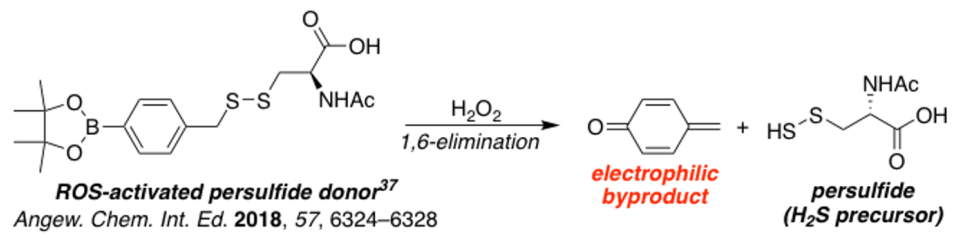

\section{this work}
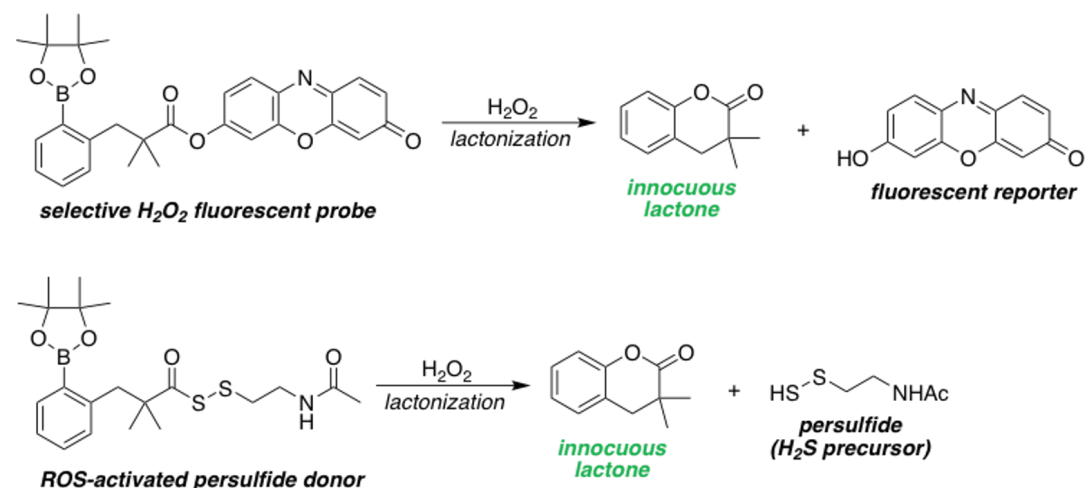

Figure 1. The use of boronate esters as a bioorthogonal trigger for hydrogen peroxide sensing. 
To this end, aryl boronate esters have long been established as highly selective, bioorthogonal triggers for hydrogen peroxide $\left(\mathrm{H}_{2} \mathrm{O}_{2}\right)$-sensing. ${ }^{[41-45]}$ Naturally, many of these studies have highlighted the selective release of payload, via a 1,6-elimination, from the intermediate phenol that forms as a result of boronate ester oxidation. This has resulted in the development of numerous reaction-based fluorescent probes and prodrugs-including several RSS donors-that are selectively responsive towards $\mathrm{H}_{2} \mathrm{O}_{2}$ (Figure 1). ${ }^{[36-43]}$ However, given the highly electrophilic 1,4-quinone methide that ultimately forms via this mechanistic pathway, the physiological application of these molecules is often limited. ${ }^{[46,47]}$ With this in mind, we sought to develop a novel hydrogen peroxide-sensing motif that would ensure the selective and efficient release of desired payload but without the formation of deleterious byproducts. Herein, we disclose these efforts which led to our development of a novel reaction-based fluorescent probe for the selective detection and imaging of $\mathrm{H}_{2} \mathrm{O}_{2}$ in water and in living cells, as well as the development of an ROS-activated persulfide donor that was shown to provide impressive cellular protection against oxidative stress.

\section{Results and Discussion}

Taking inspiration from Wang and co-workers and their use of a "trimethyl lock"[48] system that was shown to release persulfides, and other RSS, in response to esterases, ${ }^{[49-51]}$ we hypothesized that a complementary persulfide donor that responds to ROS may be feasible if the acetate functional group in their design were replaced with an $\mathrm{H}_{2} \mathrm{O}_{2}$-responsive moiety, such as a

A)
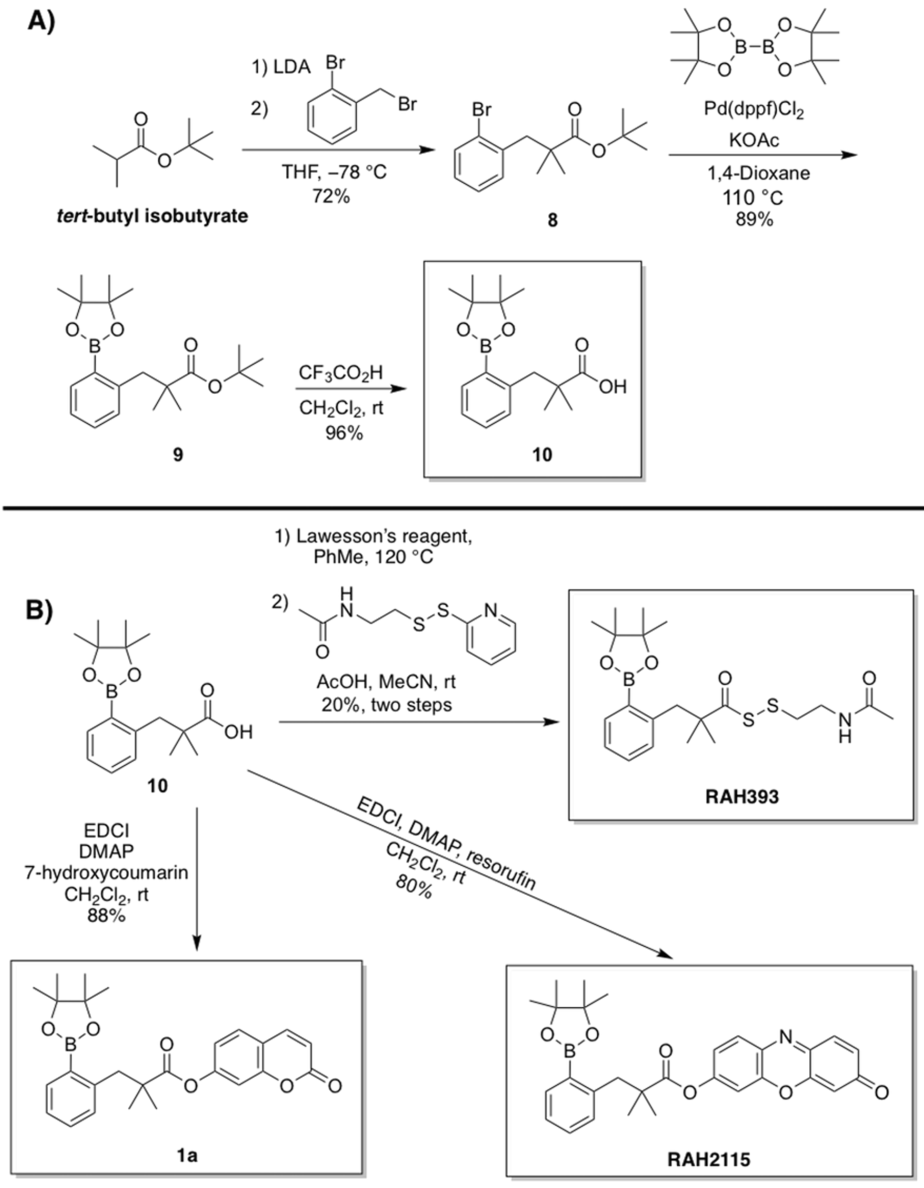

Scheme 1. (A) A convenient synthesis of key intermediate 10 from tert-butyl isobutyrate. Intermediate 10 was accessed in three steps and with an overall yield of $62 \%$. (B) Facile conversion of 10 into $\mathrm{H}_{2} \mathrm{O}_{2}$ reaction-based fluorescent probes (1a and $\mathrm{RAH2115}$ ) and an ROS-activated persulfide donor (RAH393). 
boronate ester. Then, upon boronate ester oxidation, and given the presence of a gem-dimethyl group (i.e. the Thorpe-Ingold effect), ${ }^{[52]}$ the ensuing phenol would undergo rapid lactonization resulting in persulfide release with the sole production of an innocuous lactone as its major organic byproduct (Figure 1).

To test this hypothesis, we first sought to generate compound 10 as we speculated that the carboxylic acid functionality would serve as a convenient handle, enabling subsequent conjugation reactions with ease (Scheme 1). Accordingly, our synthesis commenced by first treating tert-butyl isobutyrate with LDA followed by the slow addition of 2-bromobenzyl bromide which provided $\mathbf{8}$ in $72 \%$ yield. Once in hand, compound $\mathbf{8}$ then underwent a Miyaura borylation reaction which furnished $\mathbf{9}$ in $89 \%$ yield. The tert-butyl ester group was then removed from $\mathbf{9}$ upon treatment with trifluoroacetic acid, providing our desired intermediate (10) in just three steps and with an overall yield of $62 \%$ (Scheme $1 \mathrm{~A})$.

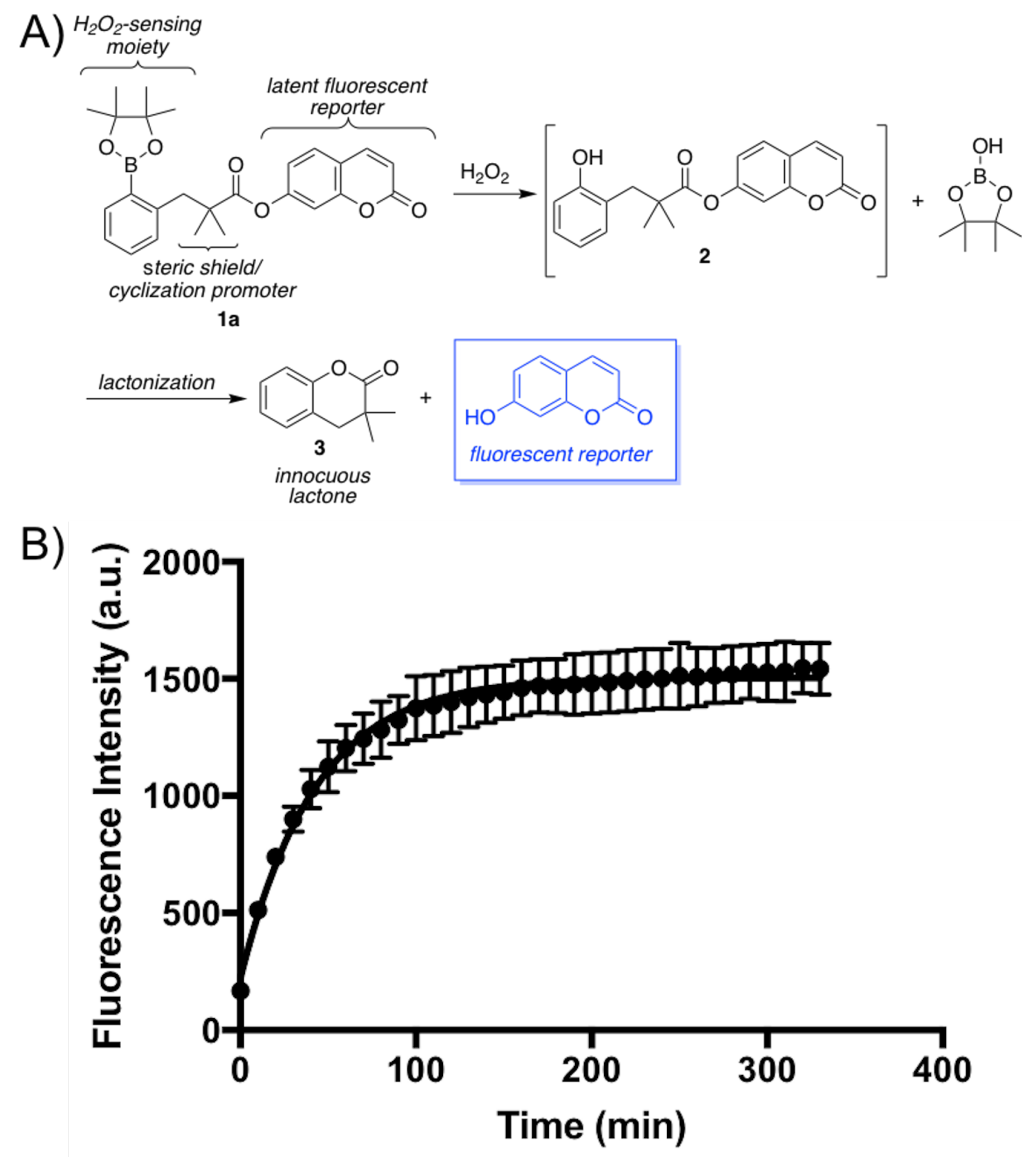

Figure 2. (A) Proposed mechanism for the selective detection of $\mathrm{H}_{2} \mathrm{O}_{2}$ with 1a. In addition to increasing the scaffold's selectivity towards $\mathrm{H}_{2} \mathrm{O}_{2}$, the gem-dimethyl group likely increases the rate of cyclization, ensuring that 2 does not accumulate as an unproductive intermediate along the reaction pathway. (B) Time-dependent fluorescence emission of $1 \mathrm{a}(20 \mu \mathrm{M})$ in the presence of $\mathrm{H}_{2} \mathrm{O}_{2}(1000 \mu \mathrm{M})$. Under these conditions, the reaction of $1 \mathrm{a}$ with $\mathrm{H}_{2} \mathrm{O}_{2}$ displayed pseudo first-order kinetics and was found to have a half-life of $29.3 \mathrm{~min}$. Plotted as the mean +/- STDEV from three independent experiments.

After the successful assembly of intermediate 10, we first coupled it to 7-hydroxycoumarin in order to access 1a (Scheme 1B). By initially appending a coumarin ester to our $\mathrm{H}_{2} \mathrm{O}_{2}$-responsive framework, we reasoned that the release of payload, in response to $\mathrm{H}_{2} \mathrm{O}_{2}$, could be easily monitored via fluorescence spectroscopy while recording the resulting increase in fluorescence intensity upon excitation at 7-hydroxycoumarin's $\lambda_{\max }$ (Figure 2). Therefore, to initially assess the reactivity of our design towards peroxides, we incubated $1 \mathrm{a}(20 \mu \mathrm{M})$ and $\mathrm{H}_{2} \mathrm{O}_{2}(1000 \mu \mathrm{M})$ in PBS 

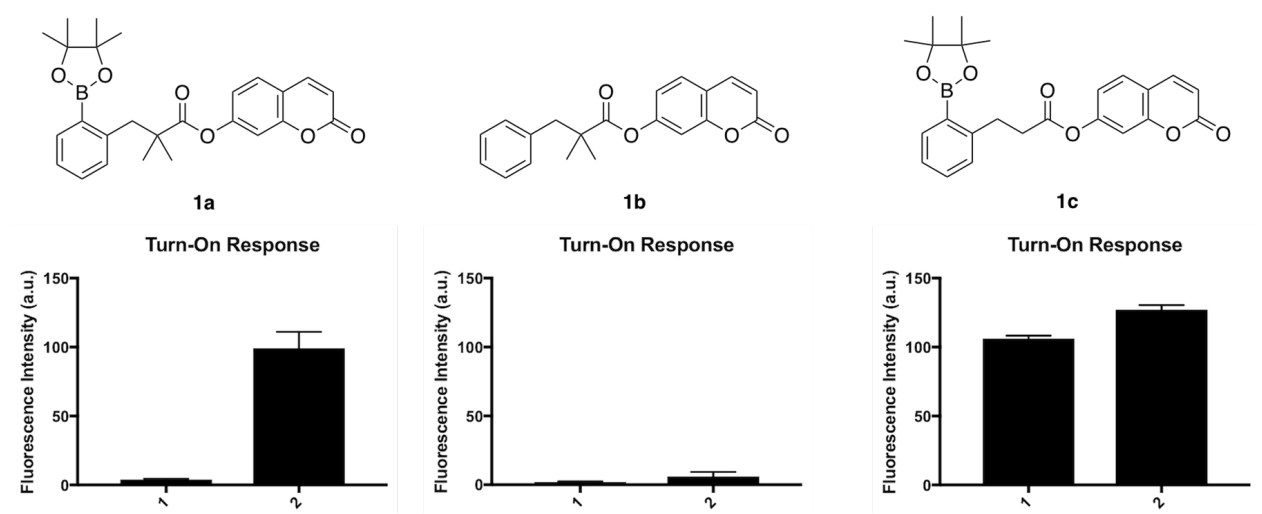

Figure 3. Turn-on fluorescence response ( $\left.\lambda_{\text {ex }}: 330 \mathrm{~nm}\right)$ of $\mathbf{1 a}, \mathbf{1 b}$, and $\mathbf{1 c}(20 \mu \mathrm{M})$ after a $3 \mathrm{~h}$ incubation period in (1) PBS buffer alone $\left(\mathrm{pH} 7.4,37^{\circ} \mathrm{C}\right)$ and (2) in the presence of $\mathrm{H}_{2} \mathrm{O}_{2}(1000 \mu \mathrm{M})$. Plotted as the mean $+/-$ STDEV from three independent experiments.

buffer $(\mathrm{pH} 7.4)$ at $37^{\circ} \mathrm{C}$. Under these conditions, we observed that the resulting fluorescence intensity increased steadily over time until it reached a maximum at roughly $1 \mathrm{~h}\left(\mathrm{t}_{1 / 2}=29.3 \mathrm{~min}\right)$, indicating complete release of the coumarin reporter (Figure 2B). To further establish our proposed mechanistic pathway, we were also able to isolate and completely characterize lactone 3 as a definitive byproduct of this transformation (see supporting information). We were, however, unsuccessful in identifying intermediate $\mathbf{2}$ at any point during the reaction, even via LCMS, indicating that it is, indeed, a short-lived intermediate that cyclizes immediately upon its formation.

In addition to facilitating the requisite ring-closing reaction, we further theorized that the strategic placement of the gem-dimethyl group alpha to the carbonyl would also serve as a convenient steric shield which would help reduce the nonspecific release of payload within biological systems. ${ }^{[53,54]}$ To further examine this hypothesis, we also synthesized control compounds 1b (which lacked the boronate ester) and 1c (which lacked the gem-dimethyl group) and compared their turn-on fluorescence to that of $\mathbf{1 a}$ in both PBS buffer alone and when coincubated with $\mathrm{H}_{2} \mathrm{O}_{2}$. As depicted in Figure 3, the results from this experiment clearly indicated that $1 \mathrm{a}$, as anticipated, was the only framework that displayed a selective turn-on fluorescence response towards $\mathrm{H}_{2} \mathrm{O}_{2}$. Conversely, $\mathbf{1 b}$-which lacked the $\mathrm{H}_{2} \mathrm{O}_{2}$-responsive moiety-showed no turn-on response while 1c-which lacked the gem-dimethyl group-was shown to be highly susceptible to hydrolysis, even in PBS buffer alone.

To further establish the practicality of our new hydrogen-peroxide sensing scaffold, we next generated RAH2115 (Scheme 1B). Given the longer excitation and emission profile of resorufin, we proposed that RAH2115 would allow us to better gauge the overall selectivity and sensitivity of our design towards $\mathrm{H}_{2} \mathrm{O}_{2}$ while confirming its potential applications within a biological setting.

The high selectivity our design towards $\mathrm{H}_{2} \mathrm{O}_{2}$ was confirmed by thoroughly screening RAH2115 against various oxidants, reductants, and nucleophiles in PBS buffer (pH 7.4) and measuring the resulting turn-on fluorescence after a $2 \mathrm{~h}$ incubation period (Figure 4A). As anticipated, RAH2115 responded well when co-incubated with $\mathrm{H}_{2} \mathrm{O}_{2}$ as a nearly 500 -fold increase in relative fluorescence intensity was observed. However, in the presence of other oxidants (glutathione disulfide, sodium nitrite, and sodium hypochlorite), reductants (glutathione, cysteine, homocysteine, sodium thiosulfate, and hydrogen sulfide), nucleophiles (lysine and serine), and salts (sodium chloride, sodium bromide, and sodium sulfate), the resulting increase in fluorescence intensity was negligible.

We also verified that the initial response rate of RAH2115 was directly proportional to the concentration of $\mathrm{H}_{2} \mathrm{O}_{2}$. This finding was deemed to be of great significance as the rate of payload release from our scaffold could then be easily tuned by varying the amount of $\mathrm{H}_{2} \mathrm{O}_{2}$. In addition, 


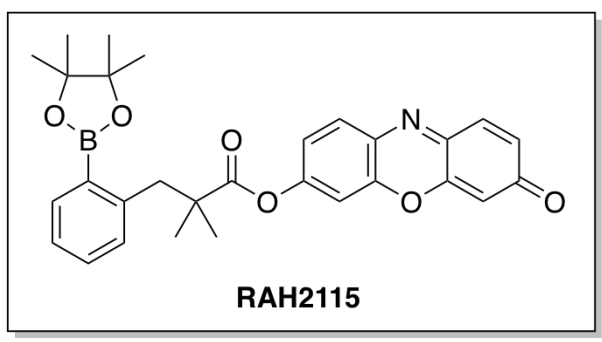

A)

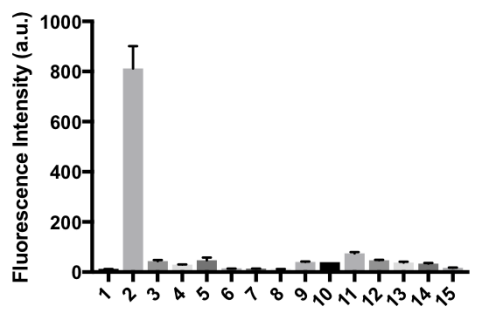

B)

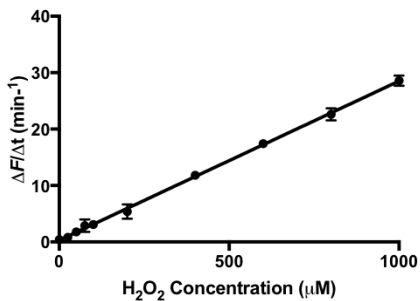

Figure 4. (A) Fluorescence response $\left(\lambda_{\text {ex }}: 570 \mathrm{~nm}\right)$ of RAH2115 $(10 \mu \mathrm{M})$ in PBS buffer and in the presence of various oxidants, reductants, nucleophiles and salts during a $2 \mathrm{~h}$ incubation period at $37^{\circ} \mathrm{C}:$ (1) PBS buffer alone; (2) $1 \mathrm{mM} \mathrm{H}_{2} \mathrm{O}_{2}$; (3) $1 \mathrm{mM}$ glutathione; (4) $1 \mathrm{mM}$ glutathione disulfide; (5) $1 \mathrm{mM} \mathrm{NaNO}_{2}$; (6) 1 mM cysteine; (7) $1 \mathrm{mM}$ lysine; (8) $1 \mathrm{mM}$ serine; (9) $1 \mathrm{mM} \mathrm{NaCl}$; (10) $1 \mathrm{mM} \mathrm{NaBr}$; (11) $1 \mathrm{mM}$ homocysteine; (12) $100 \mu \mathrm{M} \mathrm{Na} 2 \mathrm{~S}$; (13) $1 \mathrm{mM}$ sodium sulfate; (14) $1 \mathrm{mM}$ sodium thiosulfate; (15) $1 \mathrm{mM} \mathrm{NaOCl}$. Plotted as the mean +/- STDEV from three independent experiments $(B)$ The change in initial rates of increasing fluorescence intensity of RAH2115 (10 mM) upon exposure to higher concentrations of $\mathrm{H}_{2} \mathrm{O}_{2}$. Excellent linearity was observed with an $R^{2}$ of 0.99 . Plotted as the mean $+/-$ STDEV from three independent experiments

this finding also confirmed that reaction-based fluorescent probes based off of this design (i.e. RAH2115) could be used to accurately quantify the amount of $\mathrm{H}_{2} \mathrm{O}_{2}$ in buffered solutions. Indeed, as depicted in Figure 4B, when the initial rates of increasing fluorescence intensity of RAH2115 were plotted versus hydrogen peroxide concentration, excellent linearity between $0-1 \mathrm{mM}$ was observed $\left(R^{2}=0.99\right)$. Moreover, we were able to determine a lower detection limit for RAH2115 and found it to be in the low micromolar range.

To further validate the potential uses of our $\mathrm{H}_{2} \mathrm{O}_{2}$-sensing framework within a biological context, we next showed that probe RAH2115 could be used to image hydrogen peroxide within living cells. Cultured HeLa (human cervical cancer) cells were incubated with RAH2115 (10 $\mu \mathrm{M})$ for $1 \mathrm{~h}$ and then washed to remove any excess probe. Under these conditions, we did not observe any fluorescent cells (Figure 5A). However, given the detection limit of RAH2115 and the natural abundance of peroxide within most cells $(<1 \mu \mathrm{M}),{ }^{[55]}$ this finding is not unexpected and instead further signifies the stability of our framework, even within a complex biological setting. Conversely, we found that when HeLa cells were first pre-treated with paraquat, a known $\mathrm{H}_{2} \mathrm{O}_{2}$ stimulator, ${ }^{56,57]}$ the addition of RAH2115 resulted in a strong red fluorescence within cells, further accentuating the ability of our framework to release a payload of interest under conditions of oxidative stress (Figure 5A).

Given these results, we were further intrigued at the prospect of converting our new $\mathrm{H}_{2} \mathrm{O}_{2}-$ sesning scaffold into an ROS-responsive persulfide donor. In particular, the initial cellular studies suggested that such a donor would likely afford the preferential release of persulfides within biological systems with elevated levels of ROS, thereby providing a useful chemical tool for probing the therapeutic potential of persulfides and their ability to combat oxidative stress-related diseases.

Motivated by the earlier works of Xian and Matson, we first generated compound $4 \mathrm{a}$ as a convenient way to monitor persulfide release from our newly derived scaffold ${ }^{[14,37]}$ As outlined in Figure $6 \mathrm{~A}$, we predicted that upon reacting with peroxides, the resulting phenol would once again undergo rapid lactonization resulting in persulfide release. Once liberated, the free persulfide would then undergo a second cyclization onto the proximal ester with the concurrent release of 

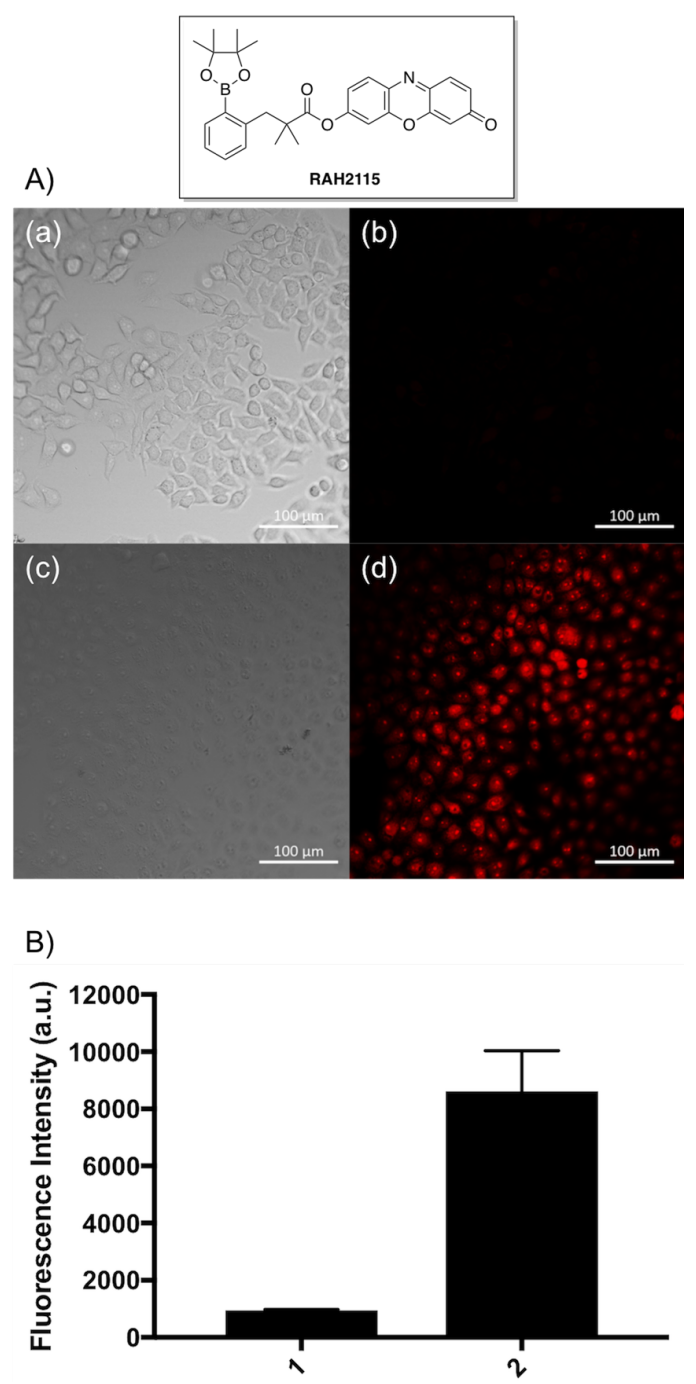

Figure 5. (A) Visualization of endogenous $\mathrm{H}_{2} \mathrm{O}_{2}$ in live HeLa cells with RAH2115 (10 $\mu$ M). Imaging: ex: $561 \mathrm{~nm}$, em: $587 \mathrm{~nm}$. (a) and (b): In the absence of paraquat (control); (c) and (d): With the addition of paraquat (10 mM), a known ROS stimulator. Scale bar set to $100 \mu \mathrm{m}$. (B) Resulting fluorescence intensity of corresponding cellular images. Column 1: In the absence of paraquat (control); Column 2: With the addition of paraquat (10 $\mathrm{mM}$ ). Values are expressed as the mean +/- STDEV over three separate images.

7-hydroxycoumarin. The resulting increase in fluorescence intensity at the characteristic wavelength of 7-hydroxycoumarin could then be easily monitored and would be directly proportional to the amount of released persulfide. As a control, we also generated compound $\mathbf{4 b}$ which lacked the boronate ester, rendering this proposed mechanistic pathway nonoperational.

We tested these hypotheses by exposing both $4 \mathbf{a}$ and $\mathbf{4 b}(20 \mu \mathrm{M})$ to $\mathrm{H}_{2} \mathrm{O}_{2}(200 \mu \mathrm{M})$ in PBS buffer ( $\mathrm{pH} \mathrm{7.4)}$ at $37^{\circ} \mathrm{C}$ and monitoring the resulting fluorescence intensity over a period of 3 hours (Figure 6B). While the relative fluorescence intensity was found to significantly increase over time with $\mathbf{4 a}$, when $\mathbf{4 b}$ was used, the subsequent increase in fluorescence was found to be trivial. Moreover, when 4a was incubated in PBS buffer alone, it was found to display a nearly identical fluorescence profile to that of $\mathbf{4 b}$ indicating that the slight increase in fluorescence over time is likely attributable to the direct hydrolysis of the more labile coumarin ester. Under these conditions, the reaction between $4 a$ and $\mathrm{H}_{2} \mathrm{O}_{2}$ was found to have a half-life of 60.5 min and with a pseudo first-order rate constant of $0.012 \mathrm{~min}^{-1}$-values which are comparable to those of other previously reported ROS-activated RSS donors. ${ }^{[37,38]}$ 


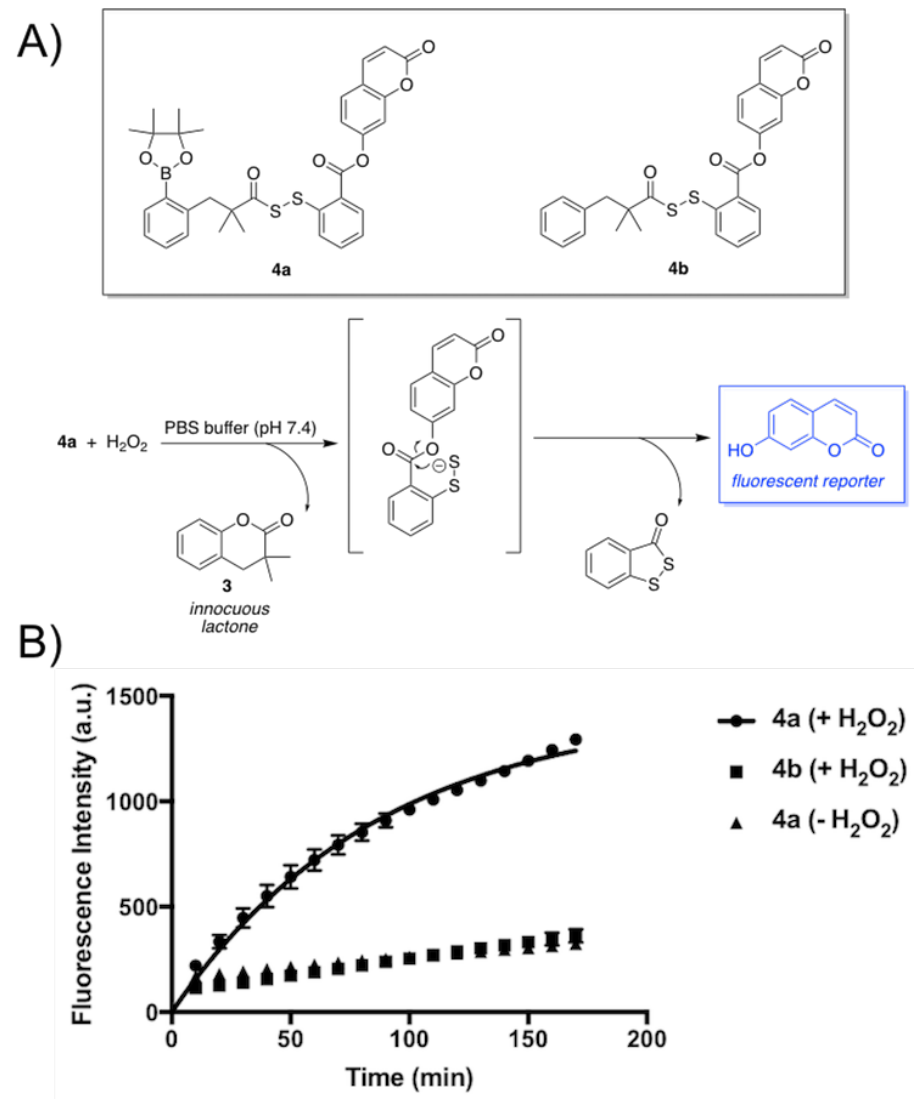

Figure 6. Time-dependent fluorescence emission of $4 \mathrm{a}(20 \mu \mathrm{M})$ in the presence and absence of $\mathrm{H}_{2} \mathrm{O}_{2}(200$ $\mu \mathrm{M})$. As a control, $\mathbf{4 b}$ was also assayed under the same conditions. Together, these results indicate that the observed increase in fluorescence intensity is directly proportional to persulfide release. Under these conditions, the reaction between 4a with $\mathrm{H}_{2} \mathrm{O}_{2}$ displayed pseudo first-order kinetics with a half-life of 60.5 min and a $k_{\mathrm{obs}}$ of $0.012 \mathrm{~min}^{-1}$. Plotted as the mean $+/-$ STDEV from three independent experiments.

After further confirming the stability of our scaffold, as well as its ability to selectively release persulfides in response to $\mathrm{H}_{2} \mathrm{O}_{2}$, we next generated persulfide donor RAH393 (Scheme 1B). Our motivation for using $\mathrm{N}$-acetylcysteamine was due to its reported high biocompatibility and strong antioxidant effects which would likely render its persulfide as a promising combatant of ROS. ${ }^{[58]}$ However, prior to evaluating the therapeutic potential of RAH393, we first confirmed the ability of our scaffold to release this specific persulfide in response to $\mathrm{H}_{2} \mathrm{O}_{2}$. To accomplish this, we incubated RAH393 along with 2,4-dinitrofluorobenzene (DNFB) in an effort to trap the ensuing persulfide as a more stable disulfide (7, Scheme 2). For comparison, we also generated control compound 5, which again lacked the requisite $\mathrm{H}_{2} \mathrm{O}_{2}$-responsive moiety. During our studies, we found that upon incubating RAH393 $(200 \mu \mathrm{M})$ with $\mathrm{H}_{2} \mathrm{O}_{2}(1 \mathrm{mM})$ and DNFB $(1 \mathrm{mM})$, persulfide release indeed occurs as formation of disulfide 7 was confirmed by LCMS. (Figures S1 and S4). In addition, persulfide release from our scaffold was further verified by the linear increase in the production of lactone 3, again verified by LCMS, over a period of $25 \mathrm{~min}$ (Figures S1 and S3). Throughout this study, we were still unable to identify, via LCMS, the intermediate phenol that precedes lactone formation, further verifying that once our scaffold reacts with $\mathrm{H}_{2} \mathrm{O}_{2}$, the subsequent cyclization event is rapid. These observations, along with the fact that $\mathbf{5}$ proved unsuccessful in yielding 7 under identical conditions (Figures S2 and S4), further corroborates that persulfide release does occur from our scaffold, in response to peroxides, and via our proposed mechanistic pathway-as opposed to nonspecific hydrolysis.

Lastly, we aimed to evaluate RAH393 within a biological setting. After initially determining that neither RAH393 nor its resulting lactone (3) were toxic towards HeLa cells (Figures S5 and S6), we set out to gauge the protective effects of RAH393 on cultured HeLa cells which were 


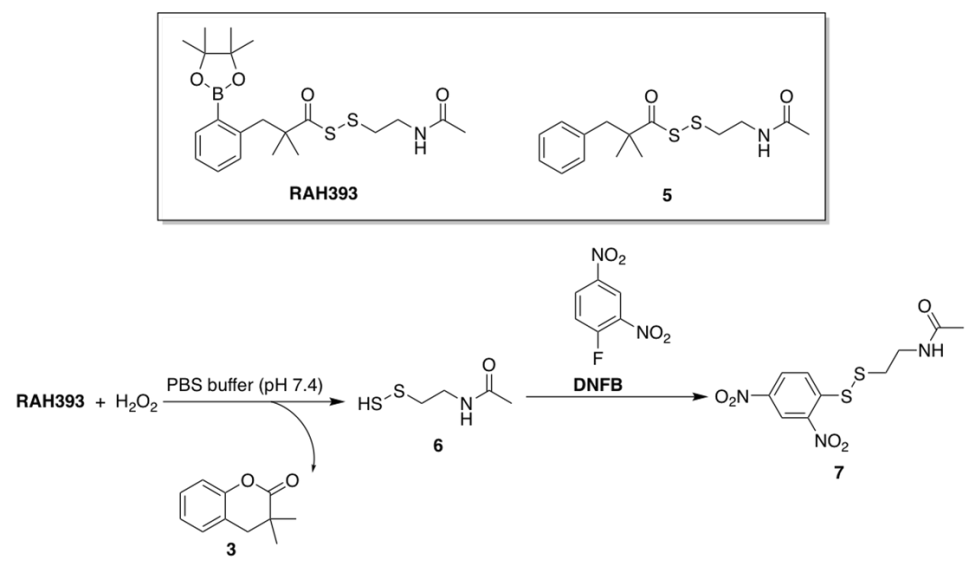

Scheme 2. Validation of RAH393 as an ROS-activated persulfide donor. DNFB was used in an effort to trap the released persulfide (6) as a more stable disulfide (7). The formation of both 7 and 3 was confirmed via LCMS.

under oxidative stress. In our hands, we found that incubating HeLa cells with $200 \mu \mathrm{M} \mathrm{H}_{2} \mathrm{O}_{2}$ over a period of 1 hour reduced cell viability to just 33\% (Figure S7). However, we observed that when HeLa cells were first pre-treated with RAH393 $(200 \mu \mathrm{M})$ prior to the 1-hour incubation period with $\mathrm{H}_{2} \mathrm{O}_{2}(200 \mu \mathrm{M})$, an astounding $100 \%$ increase in cell viability was observed (Figure 7). As a control, 5 was again tested alongside RAH393 and, under identical conditions, was found to provide no protection against $\mathrm{H}_{2} \mathrm{O}_{2}$-induced oxidative stress. Therefore, the results from this study clearly highlight the protective effects of RAH393 and its potential as a combatant of oxidative stress-related diseases.
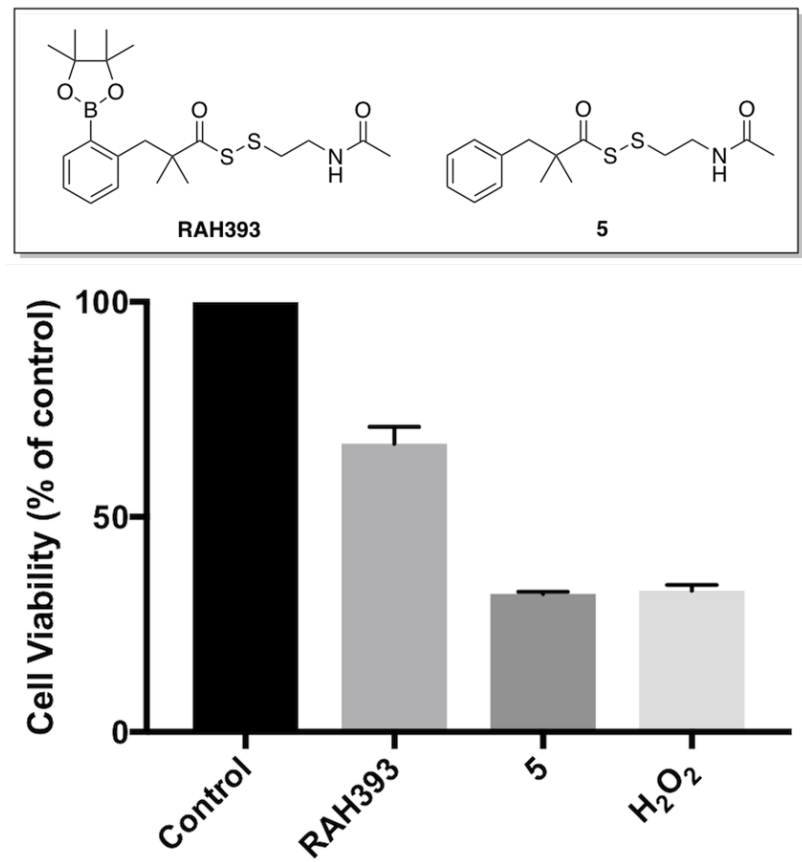

Figure 7. Resulting viability of HeLa cells upon pre-treatment with RAH393 (200 $\mu \mathrm{M})$ or $\mathbf{5}(200 \mu \mathrm{M})$ for $1 \mathrm{~h}$ followed by exposure to $\mathrm{H}_{2} \mathrm{O}_{2}(200 \mu \mathrm{M})$ for an additional $1 \mathrm{~h}$. Results are expressed as the mean + - STDEV ( $\mathrm{n}=3-6$ for each treatment group). 


\section{Conclusion}

In summary, we have rationally designed a novel $\mathrm{H}_{2} \mathrm{O}_{2}$-sensing platform that operates via an unprecedented mechanistic pathway that avoids the production of deleterious byproducts, such as 1,4-quinone methides. Payload release from this framework was found to be exceptionally selective and only triggered by the presence of $\mathrm{H}_{2} \mathrm{O}_{2}$. As a result of this high selectivity, we were successful in the development of a novel reaction-based fluorescent probe for the selective detection and imaging of $\mathrm{H}_{2} \mathrm{O}_{2}$ in water and in living cells and in the construction of a unique ROSactivated persulfide donor that was shown to provide impressive cellular protection against oxidative stress. Thus, given its high versatility, we envision many potential applications for our new $\mathrm{H}_{2} \mathrm{O}_{2}$-sensing framework, including the development of novel prodrugs used to treat any of the numerous ailments which are linked to the uncontrolled production of ROS, such as cancer, inflammation, and cardiovascular disease.

\section{Acknowledgements}

We are grateful for financial support from The Center for Molecular Signaling (internal pilot grant) and Wake Forest University (start-up funds). We would also like to sincerely thank Dr. Heather Brown-Harding for help with cellular microscopy, Dr. Chris Tracy for offering advice on mass spectrometry and LCMS studies, and Dr. Marcus Wright for assisting with NMR.

\section{References}

[1] X. Cao, L. Ding, Z. Xie, Y. Yang, M. Whiteman, P. K. Moore, J.-S. Bian, Antioxid. Redox Signal. 2019, 31, 1-38.

[2] H. Kimura, Amino Acids 2011, 41, 113-121.

[3] M. R. Filipovic, J. Zivanovic, B. Alvarez, R. Banerjee, Chem. Rev. 2018, 118, 1253-1337.

[4] R. Wang, Proc. Natl. Acad. Sci. 2012, 109, 8801-8802.

[5] A. Papapetropoulos, R. Foresti, P. Ferdinandy, Br. J. Pharmacol. 2015, 172, 1395-1396.

[6] G. Cirino, V. Vellecco, M. Bucci, Br. J. Pharmacol. 2017, 174, 4021-4031.

[7] T. Ida, T. Sawa, H. Ihara, Y. Tsuchiya, Y. Watanabe, Y. Kumagai, M. Suematsu, H. Motohashi, S. Fujii, T. Matsunaga, M. Yamamoto, K. Ono, N. O. Devarie-Baez, M. Xian, J. M. Fukuto, T. Akaike, Proc. Natl. Acad. Sci. USA 2014, 111, 7606-7611.

[8] K. Ono, T. Akaike, T. Sawa, Y. Kumagai, D. A. Wink, D. J. Tantillo, A. J. Hobbs, P. Nagy, M. Xian, J. Lin, J. M. Fukuto, Free Radic. Biol. Med. 2014, 77, 82-94.

[9] C. Yang, N. O. Devarie-Baez, A. Hamsath, X. Fu, M. Xian, Antioxid. Redox Signal. 2019.

[10] N. Lau, M. D. Pluth, Curr. Opin. Chem. Biol. 2019, 49, 1-8.

[11] C.-M. Park, L. Weerasinghe, J. J. Day, J. M. Fukuto, M. Xian, Mol. Biosyst. 2015, 11, 1775-1785.

[12] B. Yu, Z. Yuan, X. Yang, B. Wang, Antioxid. Redox Signal. 2020.

[13] E. Cuevasanta, M. Lange, J. Bonanata, E. L. Coitiño, G. Ferrer-Sueta, M. R. Filipovic, B. Alvarez, J. Biol. Chem. 2015, $290,26866-26880$.

[14] W. Chen, C. Liu, B. Peng, Y. Zhao, A. Pacheco, M. Xian, Chem. Sci. 2013, 4, 2892-2896.

[15] W. Chen, E. W. Rosser, T. Matsunaga, A. Pacheco, T. Akaike, M. Xian, Angew. Chem. Int. Ed. 2015, 54, 13961-13965.

[16] R. C. O. Zanardo, V. Brancaleone, E. Distrutti, S. Fiorucci, G. Cirino, J. L. Wallace, R. C. O. Zanardo, V. Brancaleone, E. Distrutti, S. Fiorucci, G. Cirino, J. L. Wallace, FASEB J. 2006, 20, 2118-2120.

[17] W. Zhao, EMBO J. 2001, 20, 6008-6016.

[18] L. Li, M. Whiteman, Y. Y. Guan, K. L. Neo, Y. Cheng, S. W. Lee, Y. Zhao, R. Baskar, C.-H. Tan, P. K. Moore, Circulation 2008, 117, $2351-2360$.

[19] Y. Zhao, J. Kang, C.-M. Park, P. E. Bagdon, B. Peng, M. Xian, Org. Lett. 2014, 16, 4536-4539.

[20] P. Chauhan, P. Bora, G. Ravikumar, S. Jos, H. Chakrapani, Org. Lett. 2017, 19, 62-65.

[21] M. M. Cerda, M. D. Hammers, M. S. Earp, L. N. Zakharov, M. D. Pluth, Org. Lett. 2017, 19, $2314-2317$.

[22] Y. Zheng, B. Yu, Z. Li, Z. Yuan, C. L. Organ, R. K. Trivedi, S. Wang, D. J. Lefer, B. Wang, Angew. Chem. Int. Ed. 2017, 56, 11749-11753.

[23] B. Severino, A. Corvino, F. Fiorino, P. Luciano, F. Frecentese, E. Magli, I. Saccone, P. Di Vaio, V. Citi, V. Calderone, L. Servillo, R. Casale, G. Cirino, V. Vellecco, M. Bucci, E. Perissutti, V. Santagada, G. Caliendo, Eur. J. Med. Chem. 2018, 143, $1677-1686$.

[24] Y. Zhao, A. K. Steiger, M. D. Pluth, Angew. Chem. Int. Ed. 2018, 57, 13101-13105.

[25] Y. Zhao, H. Wang, M. Xian, J. Am. Chem. Soc. 2011, 133, 15-17.

[26] Y. Zhao, A. K. Steiger, M. D. Pluth, Chem. Commun. 2018, 54, 4951-4954.

[27] M. M. Cerda, Y. Zhao, M. D. Pluth, J. Am. Chem. Soc. 2018, 140, 12574-12579.

[28] V. S. Khodade, J. P. Toscano, J. Am. Chem. Soc. 2018, 140, 17333-17337.

[29] M. M. Cerda, T. D. Newton, Y. Zhao, B. K. Collins, C. H. Hendon, M. D. Pluth, Chem. Sci. 2019, 10, $1773-1779$.

[30] S. G. Bolton, M. M. Cerda, A. K. Gilbert, M. D. Pluth, Free Radic. Biol. Med. 2019, 131, 393-398.

[31] C. R. Powell, K. Kaur, K. M. Dillon, M. Zhou, M. Alaboalirat, J. B. Matson, ACS Chem. Biol. 2019, 14, 1129-1134.

[32] M. Whiteman, P. G. Winyard, Expert Rev. Clin. Pharmacol. 2011, 4, 13-32.

[33] Y. Zhao, C. Yang, C. Organ, Z. Li, S. Bhushan, H. Otsuka, A. Pacheco, J. Kang, H. C. Aguilar, D. J. Lefer, M. Xian, J. Med. Chem. 2015, 58, $7501-7511$. 
[34] P. De Cicco, E. Panza, G. Ercolano, C. Armogida, G. Sessa, G. Pirozzi, G. Cirino, J. L. Wallace, A. lanaro, Pharmacol. Res. $2016,114,67-73$.

[35] D. Gerő, R. Torregrossa, A. Perry, A. Waters, S. Le-Trionnaire, J. L. Whatmore, M. Wood, M. Whiteman, Pharmacol. Res. $2016,113,186-198$.

[36] Y. Zhao, M. D. Pluth, Angew. Chem. Int. Ed. 2016, 55, 14638-14642.

[37] C. R. Powell, K. M. Dillon, Y. Wang, R. J. Carrazzone, J. B. Matson, Angew. Chem. Int. Ed. 2018, 57, 6324-6328.

[38] P. Chauhan, S. Jos, H. Chakrapani, Org. Lett. 2018, 20, 3766-3770.

[39] P. Bora, P. Chauhan, S. Manna, H. Chakrapani, Org. Lett. 2018, 20, 7916-7920.

[40] K. Dillon, C. Powell, J. Matson, Synlett 2019, 30, 525-531.

[41] A. R. Lippert, G. C. Van de Bittner, C. J. Chang, Acc. Chem. Res. 2011, 44, 793-804.

[42] B. J. Bezner, L. S. Ryan, A. R. Lippert, Anal. Chem. 2020, 92, 309-326.

[43] H. Ye, Y. Zhou, X. Liu, Y. Chen, S. Duan, R. Zhu, Y. Liu, L. Yin, Biomacromolecules 2019, 20, $2441-2463$.

[44] C. Chung, D. Srikun, C. S. Lim, C. J. Chang, B. R. Cho, Chem. Commun. 2011, 47, 9618-9620.

[45] L. Yi, L. Wei, R. Wang, C. Zhang, J. Zhang, T. Tan, Z. Xi, Chem. - Eur. J. 2015, 21, 15167-15172.

[46] T. J. Monks, R. P. Hanzlik, G. M. Cohen, D. Ross, D. G. Graham, Toxicol. Appl. Pharmacol. 1992, 112, 2-16.

[47] T. Monks, D. Jones, Curr. Drug Metab. 2002, 3, 425-438.

[48] M. N. Levine, R. T. Raines, Chem. Sci. 2012, 3, 2412-2420.

[49] Y. Zheng, B. Yu, K. Ji, Z. Pan, V. Chittavong, B. Wang, Angew. Chem. Int. Ed. 2016, 55, 4514-4518.

[50] B. Yu, Y. Zheng, Z. Yuan, S. Li, H. Zhu, L. K. De La Cruz, J. Zhang, K. Ji, S. Wang, B. Wang, J. Am. Chem. Soc. 2018, 140, 30-33.

[51] Z. Yuan, Y. Zheng, B. Yu, S. Wang, X. Yang, B. Wang, Org. Lett. 2018, 20, 6364-6367.

[52] M. E. Jung, G. Piizzi, Chem. Rev. 2005, 105, 1735-1766.

[53] S. I. Suarez, R. Ambrose, M. A. Kalk, J. C. Lukesh, Chem. - Eur. J. 2019, 25, 15736-15740.

[54] T. T. Talele, J. Med. Chem. 2018, 61, 2166-2210.

[55] J. R. Stone, S. Yang, Antioxid. Redox Signal. 2006, 8, 243-270.

[56] B. C. Dickinson, C. J. Chang, J. Am. Chem. Soc. 2008, 130, 9638-9639.

[57] A. L. McCormack, M. Thiruchelvam, A. B. Manning-Bog, C. Thiffault, J. W. Langston, D. A. Cory-Slechta, D. A. Di Monte, Neurobiol. Dis. 2002, 10, 119-127.

[58] F. Shams, D. Oladiwura, K. Ramaesh, I. Livingstone, Clin. Ophthalmol. 2014, 2077-2084. 